\title{
A Poesia para Benveniste ${ }^{1}$
}

\author{
Poetry for Benveniste
}

\author{
Adilson Ventura ${ }^{2}$ \\ Universidade Estadual do Sudoeste da Bahia
}

\begin{abstract}
- RESUMO: A poesia, por ser um objeto que lida com a língua, deveria ser algo de grande interesse para linguistas, principalmente se pensarmos que ela, de algum modo, pode lidar com a língua de um modo bem específico. Essa questão nos toma de uma inquietação muito grande, já que, de um modo geral, temos poucos linguistas que se debruçaram diretamente nos estudos poéticos. Outros, de uma forma indireta, consideraram alguns aspectos da poesia, entretanto, sem fazer análises de poemas. Assim esse trabalho objetiva analisar os textos de Benveniste, linguista conhecido pelos estudos da enunciação. Para isso, fizemos, em um primeiro momento, um pequeno debate sobre sua teoria. Logo após, analisamos as ocorrências da palavra poesia em seus textos, a partir do escopo teórico da Semântica do Acontecimento, teoria proposta por Guimarães (2002, 2004, 2011). Utilizamos como método de análise os mecanismos enunciativos de produção de sentidos, que são a reescrituração e a articulação. Como resultados, chegamos à conclusão de que, para Benveniste, a poesia é um uso particular da linguagem pelo poeta.
\end{abstract}

- PALAVRAS-CHAVE: Semântica. Enunciação. Poesia.

- ABSTRACT: Poetry, as an object that deals with language, should be of great interest to linguists, especially if we think that it can somehow handle language in a very specific way. This question is of great concern to us since in general, we have very few linguists who have directly addressed poetic studies. Others indirectly considered some aspects of poetry, however, without making poem analyzes. Thus this work aims to analyze the texts of Benveniste, linguist known for the studies of enunciation. To do this, we had, at first, a little debate about his theory. Soon after, we analyze the occurrences of the word poetry in their texts, from the theoretical scope of the Semantic of Event, the theory proposed by Guimarães $(2002,2004,2011)$. We use as a method of analysis the enunciative mechanisms of meaning production, which are rewriting and articulation. As a result, we come to the conclusion that for Benveniste poetry is a particular use of language by the poet.

- KEYWORDS: Semantics. Enunciation. Poetry.

\section{Introdução}

A poesia sempre foi algo que nos chamou muito a atenção, na medida em que produz, em nossa sociedade, efeitos diversos. Podemos pensar, de um modo bem geral, o quanto poemas fazem pessoas se emocionarem, pensarem em situações da própria vida, etc. Sendo assim, pensar a poesia é pensar um objeto que, de um modo geral, é do

\footnotetext{
${ }^{1}$ Este artigo é uma parte adaptada de minha tese de doutorado, intitulada: O Sentido da Palavra Poesia nas Ciências da Linguagem, feita sob a orientação do prof. Dr. Eduardo Guimarães.

${ }^{2}$ Doutor em Linguística pela UNICAMP. Professor adjunto do Departamento de Estudos Linguísticos e Literários (DELL) da Universidade Estadual do Sudoeste da Bahia (UESB); Professor do programa de pós-graduação em linguística (PPGLIN); do PROFLETRAS; membro de grupo de estudos GEPES.
} 
interesse da sociedade, já que é algo tão presente na vida cotidiana. E, além de ser algo do cotidiano, é também uma questão linguística, o que nos leva a pensar como se pode tratar a poesia a partir de um lugar científico. Essa questão sempre nos trouxe inquietações, o que nos levou a trabalhar, em nosso doutorado, a relação da poesia e as Ciências da Linguagem. Em nossa tese (VENTURA, 2012), construímos um corpus, selecionando alguns estudiosos da língua(gem) e analisando o modo como cada um traz, em seus estudos, possíveis relações com a poesia. Assim, para esse nosso trabalho, fizemos um recorte de nossa tese de doutorado para promover uma reflexão de que modo um linguista, Émile Benveniste, traz essa relação entre esses dois campos. Para isso, trouxemos uma discussão de alguns aspectos teóricos desenvolvidos por esse linguista, logo após, apresentamos algumas análises de recortes específicos de seus textos, os quais há uma relação entre a poesia e os estudos linguísticos.

\section{Aporte Teórico}

Para os nossos propósitos nesse trabalho, situaremo-nos teoricamente na Semântica do Acontecimento, teoria proposta por Eduardo Guimarães. Assim, consideramos que o lugar para os estudos do sentido é a enunciação, o acontecimento do dizer. Diferentemente do que para Benveniste, a enunciação aqui é considerada como uma relação do falante com a língua, relação essa que é o objetivo de toda e qualquer descrição. Para realizar essa descrição, recorremos a dois mecanismos enunciativos de produção de sentidos, que são a reescrituração e a articulação. A primeira é relativa aos modos como uma mesma expressão aparece sendo redita ao longo de um mesmo texto, e, ao ser redita, constitui os sentidos dessa expressão no texto. Além da reescrituração, a articulação também está na constituição dos sentidos, na medida em que se observa uma expressão em relação a outras expressões no texto, que não são reescrituras e estão numa relação de contiguidade, ou seja, numa relação próxima à palavra e suas reescrituras. Também utilizamos o conceito da paráfrase que é

\footnotetext{
A paráfrase é o mecanismo que o analista lança mão para interpretar, ou, em outras palavras, ela é um teste. Em um acontecimento específico, o analista testa as possibilidades de paráfrase para entender os sentidos de determinada enunciação; testa a performatividade do enunciado. (SOBRAL e VENTURA, 2019, p.353)
}

A partir das descrições, chegamos ao DSD, que é uma representação gráfica dos sentidos de uma palavra em um texto específico.

\section{Benveniste: debate teórico e análises}

Benveniste é um linguista de importância central nos estudos semânticos, especialmente no que toca a questões relativas à enunciação e à subjetividade na língua. Em seus estudos ele apresenta análises detalhadas de vários fatos linguísticos, trazendo à tona questões por vezes tratadas por outros estudiosos sem levar em conta aspectos que ele prioriza. Nestas análises incluem-se, decisivamente, importantes análises históricas, nas quais ele demonstra um vasto conhecimento de detalhes relativos a diversas línguas e culturas, assim com o conhecimento de alguns textos decisivos para o estabelecimento de novas questões e também para o desenvolvimento de métodos e de teorias para as Ciências da Linguagem em geral e para a Linguística em particular. 
Benveniste não se dedicou aos estudos da poesia nem produziu análises de poemas, mas seus estudos podem indicar questões importantes sobre o que pode significar a poesia para as Ciências da Linguagem.

Para fazermos uma breve apresentação dos estudos linguísticos de Benveniste, escolhemos alguns pontos em que ele apresenta certas noções de importância fundamental, tanto em sua teoria como para a Linguística. Partindo de sua preocupação com o rigor científico para a produção de análises linguísticas, ele estabelece os níveis em que a análise linguística deve se dar. Para isso ele apresenta tanto o nível inferior de análise como o nível superior, sendo que o nível inferior:

\begin{abstract}
Atingimos assim, pelos processos descritos, os dois níveis inferiores da análise, o das entidades segmentáveis mínimas, os fonemas, o nível fonemático, e o dos traços distintivos, que propomos chamarem-se merismas (gr.mérisma, -atos, "delimitação, parte, pedaço"), o nível merismático. (Benveniste, 1976, p.129)
\end{abstract}

Essas entidades irão integrar outros níveis até chegar ao nível superior da análise linguística. Esse limite superior "é traçado pela frase, que comporta constituintes mas que, como adiante se mostra, não pode integrar nenhuma unidade mais alta." (idem, p. 134). A frase, mesmo sendo a unidade do discurso, não se integra a outro nível, sendo ela própria este limite. No discurso, temos um outro universo, em que a língua passa a instrumento de comunicação, ou, em outras palavras, passa a manifestação da língua na comunicação. Dessa forma Benveniste situa sua análise no universo da língua. Este universo é composto por signos formais e que devem ser observados através de procedimentos rigorosos de análise, estabelecendo assim o lugar em que devem incidir os estudos linguísticos. Com essa delimitação, ele passa a pensar na distinção entre constituinte e integrante, o qual irá tocar em uma questão fundamental da linguística, que é a relação entre forma e sentido. Para Benveniste, "Forma e sentido devem definirse um pelo outro e devem articular-se juntos em toda a extensão da língua." (Benveniste, 1976, p.135), ou seja, não há como pensar a forma sem se pensar no sentido e vice-versa. E essas relações, entre constituinte e integrante, e entre forma e sentido, se estabelecem na medida em que "a dissociação leva-nos à constituição formal; a integração leva-nos às unidades significantes." (idem). Assim temos as seguintes definições propostas por Benveniste:

A forma de uma unidade linguística define-se como a sua capacidade de dissociar-se em constituintes de nível inferior.

O sentido de uma unidade linguística define-se como a sua capacidade de integrar uma unidade de nível superior. (Idem, págs. 135 e 136)

Definidos desse modo, há uma especificação em que forma e sentido se dão no nível da frase. Essa conceituação resolve a questão entre forma e sentido dentro de seu pensamento e em análises linguísticas que também tomam essa delimitação como o lugar da análise, porém, para outros estudiosos em que a análise incide sobre outra delimitação, tais como o texto e o discurso, estas definições se tornam um pouco mais complicadas, na medida em que estes conceitos necessitam de uma especificação para poder estabelecer determinadas descrições linguísticas. Lembrando aqui que Benveniste critica vários linguistas que, por não estabelecerem definições satisfatórias para esses conceitos, retiram o sentido de seus estudos, ou seja, tentam reduzir os estudos somente à noção de forma. Para ele, por estarem juntos (forma e sentido), esta separação é impossível de ocorrer, isto é, é inútil ignorar ou expulsar o sentido dos estudos linguísticos. 
Uma outra distinção, entre as estabelecidas por Benveniste é fundamental para nossas análises, e está também ligada, por outras razões, ao funcionamento do sentido. Trata-se da distinção entre o semiótico e o semântico. Nessa separação ele considera que no semiótico as unidades são reconhecidas, isto é, trata-se do estudo dos signos, enquanto que no semântico, o que se tem a estudar é a compreensão desses signos, ou seja, deve-se compreender os sentidos.

Estabelecida a delimitação dos estudos linguísticos em Benveniste, temos outra questão de fundamental importância para ele: a questão da enunciação. Ela se articula diretamente com a distinção semiótico-semântico. Para este autor, a enunciação "é este colocar em funcionamento a língua por um ato individual de utilização" (Benveniste, 2006, p.82). Não se pode confundir a enunciação com o seu produto, que é o enunciado, mas sim pensá-la como o ato de se produzir o enunciado. Ou, em outras palavras, para Benveniste a enunciação é o ato em que o sujeito se apropria da língua e a coloca em funcionamento. Com essa definição temos que pensar a questão do sujeito nos estudos linguísticos. Para o autor, pode-se observar essa questão através de marcas na própria língua que indicam a presença do sujeito, trazendo, então, a importância de se estudar essas marcas. Podemos verificar o modo como seu pensamento avança nesse sentido a partir de um estudo bem específico, que é o estudo dos pronomes. Nesse estudo ele leva em conta os pronomes pessoais eu/tu e o pronome em que falta justamente o sujeito, que é ele. Isso faz com que o indivíduo, ao dizer eu, se apropria da língua e coloca o outro na posição de tu, o que, juntamente com alguns advérbios, tais como aqui e agora, e com o tempo presente, criam um paradigma que se coloca em oposição do paradigma do ele (lá, depois). E o tu é inserido neste mesmo paradigma do eu. Desse modo, temos que o sujeito é que se apropria da língua, com suas marcas de subjetividade, transformando-a em discurso, isto é, as unidades da língua, do semiótico, são semantizadas (o aspecto semântico) pelo sujeito (locutor) na enunciação.

Uma outra questão a se considerar são os estudos de Benveniste sobre os tempos verbais, em que ele define em dois paradigmas diferentes, tomando a distinção entre a enunciação e a do discurso. Esses paradigmas dos tempos verbais são estabelecidos a partir dos paradigmas dos pronomes, entre eu/tu e ele. Assim temos a narrativa histórica como o lugar da exclusão das formas linguísticas que marcam a presença do eu, isto é, a narrativa histórica é que se coloca como objetiva, entrando no paradigma do ele, enquanto que o plano do discurso possui as marcas linguísticas do sujeito, fazendo parte então do mesmo paradigma do eu/tu. Além disso, temos um terceiro tipo de enunciação, que Benveniste assim descreve:

\footnotetext{
Indiquemos, como entre parênteses, que a enunciação histórica e a do discurso podem, conforme o caso, conjugar-se num terceiro tipo de enunciação, no qual o discurso é referido em termos de acontecimento e transposto para o plano histórico; é o que comumente se chama discurso indireto. As regras dessa transposição implicam problemas que não serão examinados aqui. (Benveniste, 1976, p.267)
}

Dentro desse quadro teórico e levando em conta outras discussões linguísticas, ele apresenta, em um texto intitulado "Semiologia da Língua" (Benveniste, 2006), algumas discussões interessantes que, mesmo não tratando diretamente, acabam por levantar várias questões a respeito da poesia. Nesse texto, ele reflete sobre o lugar da língua entre os sistemas de signos. Para isso, ele traça um histórico sobre os estudos dos signos. Segundo Peirce e Saussure, quase ao mesmo tempo, tentam a possibilidade de uma ciência dos signos, construindo algumas teorias que influenciam todo $o$ pensamento posterior. 
Ao comentar esses dois autores, Benveniste faz uma crítica ao modo como Peirce trata a língua, pois ele não lhe dá nenhum estatuto especial dentro do estudo dos signos, posição bem diferente da adotada por Saussure, em que, no quadro geral de uma semiologia, ele apresenta a língua como objeto de ciência, e a necessidade de se diferenciar a língua da linguagem, além de colocar a Linguística como a ciência responsável pelos estudos da língua e que integra uma ciência que ainda está por surgir, que é a Semiologia. Então, partindo dessas reflexões de Saussure, Benveniste também apresenta a língua como um dos sistemas de signo, dando-lhe importância central nos estudos linguísticos e semiológicos. E essa centralidade deve-se a que a língua é uma instituição social, produzida pelo indivíduo e, ao mesmo tempo, ela se compõe de unidades fixas, que são os signos. Assim temos, como característica de todos os sistemas semiológicos, a propriedade de significar, que é seu aspecto semântico, e a sua composição em unidades de significância (signos), que é o seu aspecto semiótico.

Por outro lado há vários sistemas semióticos diferentes, tais como os signos de escrita, de cortesia, signos monetários, cultos, ritos, crenças, os signos dos variados tipos de arte, etc. E temos que cada sistema semiótico não pode ser traduzido para outro sistema semiótico, ou seja, "Isto equivale a dizer que dois sistemas semióticos de tipo diferente não podem ser mutuamente conversíveis"(Benveniste, 2006, p.54). Além dessa relação de um sistema semiótico com outro, temos também que o valor de cada signo só pode ser definido dentro de seu próprio sistema semiótico, isto é, se um signo for transposto para outro sistema semiótico, o seu valor é alterado (ou, em alguns casos, esse valor pode ser até anulado). E, por não ter essa capacidade de "tradução" de um sistema a outro, Benveniste traz uma separação entre sistemas, que se relacionam no nível semiótico entre o sistema interpretante e o sistema interpretado. Essa nova separação traz novamente a língua em uma posição muito particular dentro dos sistemas semióticos, já que "os signos da sociedade podem ser integralmente interpretados pelos signos da língua, jamais o inverso." (Idem, pág.55). Isto é, a língua é o único sistema semiótico capaz de interpretar todos os outros sistemas semióticos e também pode interpretar a si próprio.

Partindo dessa diferenciação, e para provar que a língua é o único sistema semiótico capaz de interpretar todos os outros, ele passa a fazer algumas comparações entre determinados sistemas, buscando o que é que diferencia a língua de todos. Para isso ele traz as noções de unidade e de signo, em que a unidade é a menor parte da qual determinado sistema é constituído, ou seja, as unidades é que serão relacionadas para se produzir e especificar a natureza de determinado sentido. Por sua vez, o signo seria a menor parte significante de um sistema, sendo que, nem sempre coincidem a unidade e o signo. Mas, como a língua é o sistema que recebe um estatuto bem particular, ela é feita por unidades que também, ao mesmo tempo, são signos. E isso é que lhe dá a possibilidade de ser um sistema que pode interpretar todos os outros sistemas.

Com essas colocações, ele passa a considerar alguns sistemas artísticos, produzidos pelo som e por imagens, comparando-os com o sistema linguístico. Essa comparação é de grande interesse para pensarmos a poesia, pois ele coloca de lado, para este estudo, a função estética desses sistemas. E, com isso, ele coloca em dois paradigmas diferentes as linguagens artísticas e a língua, conceituando a linguagem artística em geral da seguinte forma:

As relações significantes da "linguagem" artística são descobertas NO INTERIOR de uma composição. A arte não é jamais aqui senão uma obra de arte particular, na qual o artista instaura livremente oposições e valores que ele manipula soberanamente, não tendo nem "resposta" a dar, nem contradição a eliminar, mas somente uma visão a exprimir, segundo critérios, 
conscientes ou não, de que a composição inteira dá testemunho e torna manifesto. (Benveniste, 2006, p.60)

Nesta medida Benveniste diz que as artes só apresentam a dimensão semântica, enquanto a língua apresenta as dimensões semiótica e semântica. Este aspecto já foi comentado, por exemplo, por Meschonnic (2008). E, enquanto as artes são assim definidas, a língua é colocada como a própria significância, ou seja, ela mesma funda toda a possibilidade de comunicação e de cultura.

Deste modo Benveniste deixa um problema: se a poesia é arte, ela teria só a dimensão semântica? Mas como ela é linguagem teria as dimensões semiótica e semântica? Benveniste não levaria em conta a possibilidade da língua ser um sistema semiológico capaz de engendrar a arte? Se sim, de certo modo, para ele a poesia não seria considerada como arte. Aliada a isso, temos que ele, ao fazer análise de sistemas artísticos, já coloca que não levará em conta o valor estético, preocupando-se somente em observar o modo como esse sistema é formado.

E neste quadro é que vamos nos deparar com o que ele comenta sobre o artista, que cria sua própria semiótica. Ou seja, temos aqui a questão do sujeito que se apropria de determinadas unidades e, com elas, cria a sua obra de arte, algo que poderia se aproximar do pensamento de Austin, em que a poesia fica posta no lugar do uso nãoordinário da linguagem. Para vermos essa possibilidade de aproximação, vamos produzir uma análise da palavra poesia nesse texto de Benveniste.

Pelo que acabamos de colocar, podemos começar por reconhecer a seguinte determinação entre arte e as dimensões do funcionamento da linguagem:

Arte F semântico

Desta forma coloca-se a questão, já anteriormente indicada, de que a poesia, enquanto arte, só apresenta a dimensão semântica. Se assim fosse poderíamos dizer que teríamos as seguintes relações de determinação:

\section{Poesia F Arte F semântico}

Se observarmos com mais detalhe vemos que na obra de Benveniste, há o uso da palavra poesia de modo isolado, ou seja, temos esta palavra aparecendo em alguns de seus textos. Por isso, apresentamos um texto específico, que é "Semiologia da Língua", texto este que serviu de base para as discussões que apresentamos logo acima. Nesse texto, como já dissemos, temos uma certa discussão que podemos relacionar com a nossa pesquisa de como a poesia aparece no pensamento de alguns cientistas da linguagem.

Apesar de não usar a palavra poesia neste texto, temos uma passagem decisiva em temos as palavras poético e poética:

1- O segundo tipo de relação é a RELAÇÃO DE HOMOLOGIA, que estabelece uma correlação entre as partes de dois sistemas semióticos. Diferentemente da anterior, esta relação não está constatada, mas instaurada em virtude de conexões que se descobrem ou que se estabelecem entre dois sistemas distintos. A natureza da homologia pode variar, intuitiva ou racional, substancial ou estrutural, conceptual ou poética. "Les parfums, les couleurs et les sons se répondent". Estas "correspondências" não estão senão em Baudelaire, elas organizam seu universo poético e a criação que o reflete. (pág.62) 
Temos aqui as palavras poética e poético, sendo que poética está em uma expressão referencial, que caracteriza a natureza da homologia. Assim temos uma reescritura por enumeração de tipos diferentes para se observar as semelhanças entre os sistemas semióticos. O interessante é que, para essas comparações, Benveniste traz a concepção de poesia para os seus estudos, por estar presente nessa enumeração em que os sistemas semióticos podem entrar no que concerne ao que há de semelhante ou diferente neles.

Nesta enumeração, poética se opõe diretamente a conceptual, num dos termos da enumeração e se articula aos demais elementos, sempre em disjunção. Isto nos leva à seguinte relação:

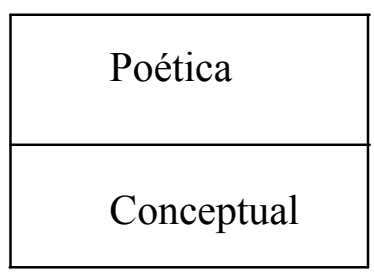

Se isto nos dá mais um elemento para o sentido de poético (poesia), temos ainda a observar a ocorrência da palavra poético no mesmo trecho analisado. Esta palavra aparece em uma expressão referencial especificando a palavra universo. Então temos universo poético. Porém este universo poético é, por sua vez, especificado por seu, isto é, o universo poético é específico de alguém, no caso aqui, de Baudelaire. E como, ao dizer sobre as "correspondências", Benveniste indica que essas ocorrências acontecem somente em Baudelaire, que fazem parte de um sistema semiótico próprio dele em suas criações artísticas. Assim, através do procedimento da paráfrase, podemos dizer que Baudelaire pode ser tomado por qualquer poeta, temos assim:

\section{Paráfrase 1:}

1.1 "Les parfums, les couleurs et les sons se répondente" são "correspondências

1.2 Elas (correspondências) estão na obra de Baudelaire

1.3 Elas organizam seu universo poético

1.4 A criação de Baudelaire reflete seu universo poético

Se considerarmos por outro lado o que disse Benveniste em

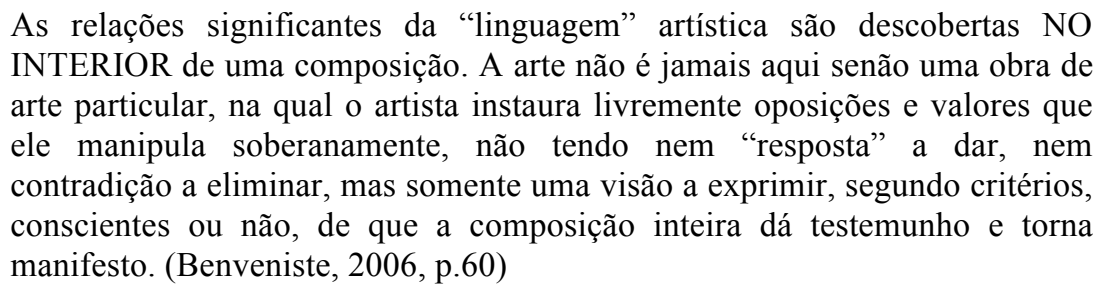

Já citado anteriormente, podemos encontrar uma articulação predicativa muito importante: "a arte é uma obra particular". E mais que isso, este caráter particular é de certo modo predicado por "o artista instaura livremente oposições e valores..."

Deste modo podemos chegar a 


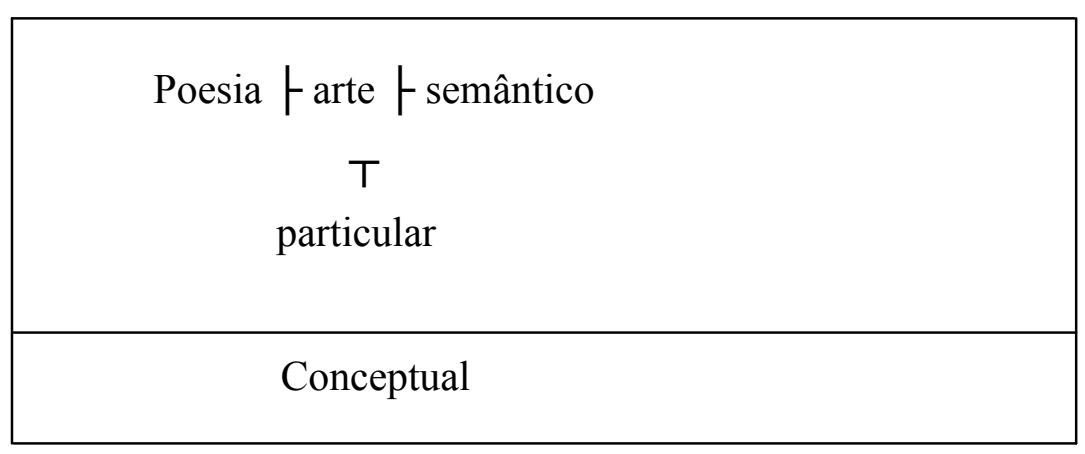

Mas falta ainda considerar dois aspectos: de um lado a predicação de que numa obra de arte particular o artista instaura livremente oposições e valores. O que está em combinação com um elemento da paráfrase acima de que "correspondência" organizam o universo poético de um poeta (Baudelaire, no caso). Isto nos leva a:

\begin{tabular}{|c|}
\hline Sistema semiótico singular do poeta \\
$\perp$ \\
Poesia $\vdash$ arte $\vdash$ semântico \\
$\mathrm{T}$ \\
particular \\
Conceptual \\
\hline
\end{tabular}

Assim podemos dizer que a posição de Benveniste de que a arte, no caso a poesia, se caracteriza por ter somente a dimensão semântica, faz sentido, na medida em que a poesia se faz não pelo sistema semiótico da língua em geral, mas por um sistema semiótico particular, que a própria "composição inteira dá testemunho e torna manifesto". Assim o sentido de sujeito não é uma determinação de poesia, ou arte, mas é quem produz arte. E esta só pode ser considerada na relação com esse sujeito, ou seja ao Artista, ao autor.

Antes de terminar, não podemos deixar de fazer referência a que Benveniste deixou manuscritos a propósito exatamente de sua análise de textos de Baudelaire, que ele cita no recorte há pouco utilizado aqui. E nestes manuscritos vamos encontrar algo como "le langage du poète sera donc, à tous points de vue, un langage iconique" (Manuscrits inédits, 2009). E isto significa para ele, na mesma passagem a que nos referimos, que a linguagem do poeta "re-présente le vécu, re-produise l'émotion, et en tant qu'elle est sonorité, la langue doit retrouver les sons qui l'évoquent".

Com isso podemos dizer que, para Benveniste, apesar de não ser dito explicitamente, o aspecto poético da língua é assimilado ao que ele indica para os sistemas semióticos relacionados à arte: "O artista cria assim sua própria semiótica: ele institui suas oposições em traços que ele próprio torna significantes em sua ordem." (Benveniste, 2006, p.59). Sendo assim, podemos dizer que, para ele, a poesia está na enunciação, na particularização do uso dos signos linguísticos dentro de um sistema 
pessoal, ou seja, o próprio indivíduo (artista) é que se apropria dos signos da língua e cria o seu sistema de significância.

Desse modo, podemos dizer que Benveniste, pela análise de seu texto no que concerne à poesia, coloca-se de um modo muito particular em uma posição semelhante à posição austiniana (principalmente se consideramos que para este a poesia estiola a performatividade), deixando a poesia no lugar do uso não-ordinário da língua, por ser um uso característico de um sistema semiológico específico de cada indivíduo.

\section{Considerações Gerais}

Assim, ao analisar os textos de E. Benveniste, linguista que se coloca em uma posição enunciativa dos estudos da linguagem, observamos que ele considera a poesia como um uso particular da linguagem pelo poeta, deixando a poesia no lugar do uso não-ordinário da língua. Porém, Benveniste traz a questão de que é preciso que os estudos da linguagem se dediquem aos aspectos "semânticos" de modo específico para que se possa desenvolver um estudo possível da poesia. Ou seja, mesmo sendo colocada como uso não-ordinário da língua, Benveniste apresenta a importância de se pensar linguisticamente um modo para se compreender a poesia.

\section{REFERÊNCIAS}

BENVENISTE. E. Problemas de Linguística Geral I. São Paulo, Companhia Editora Nacional,1976.

Problemas de Linguística Geral II. 2 2 Edição. Campinas, Pontes, 2006 . (2009) Manuscrits Inédits. In Matin, Serge, Émile Benveniste. Pour vivre

Langage. Paris: L'Atelier. 2009

GUIMARÃES, E. Semântica do Acontecimento. Campinas, Pontes. 2002 . "Domínio Semântico de Determinação". A Palavra: Forma e Sentido.

Campinas, RG/Pontes. 2007

Análise de Texto. Procedimentos, Análises, Ensino. Campinas, RG. 2011. SOUZA, D.S.; VENTURA, A. Paráfrase: um Mecanismo de Análise da Semântica do Acontecimento. In Revista Ecos vol.26, Ano 16, n 01. Cáceres. 2019 VENTURA, A. "O sentido da palavra poesia nas ciências da linguagem" Tese de doutorado. Unicamp. Campinas, SP. 2012

Recebido em: novembro de 2019.

Aprovado em: dezembro de 2019.

Como citar este trabalho:

VENTURA, A. A Poesia para Benveniste. Traços de Linguagem. V.3, n.2, p. 63-72, 2019. 